\title{
Evaluation of a real-time PCR assay for detection of Bordetella pertussis and $B$. parapertussis in clinical samples
}

\author{
KATRIN KÖSTERS, MARION RIFFELMANN and CARL HEINZ WIRSING VON KÖNIG \\ Institut für Hygiene und Laboratoriumsmedizin, Klinikum Krefeld, Lutherplatz 40, 47805 Krefeld, Germany
}

\begin{abstract}
A real-time PCR assay based on the TaqMan ${ }^{\circledR}$ technology was developed for the detection of Bordetella pertussis and $B$. parapertussis in clinical samples. The assay was evaluated with 182 specimens from 153 patients with and without symptoms of pertussis. The analytical sensitivity ranged from 0.1 to $10 \mathrm{cfu}$ for $B$. pertussis and $B$. parapertussis, respectively, and diagnostic sensitivity was $94.1 \%$ when culture was used as a reference. No sample from a patient without symptoms of pertussis was positive in PCR. Twentyfour of 28 patients who were negative by culture and positive by PCR assay met the CDC clinical case definition for pertussis; the remaining four patients had paroxysms of shorter duration. Intra- and inter-assay variation were $<5 \%$ and results were available within $4 \mathrm{~h}$.
\end{abstract}

\section{Introduction}

PCR is being used increasingly in clinical microbiology laboratories for detection of Bordetella pertussis and $B$. parapertussis [1-3]. Various PCR protocols have been developed that target different regions of the genome, e.g., insertion sequences (IS) 481 and 1001 [1,4-7], the pertussis toxin promotor region $[4,5,8,9]$, the adenylate cyclase gene [10] and the porin gene [11]. In a comparison of different PCR assays used in seven pertussis vaccine studies, the diagnostic sensitivity ranged from 73 to $100 \%$ when compared to culture, and false positive results were $<1 \%$ [12].

PCR products are routinely detected and confirmed by gel electrophoresis or methods based on the annealing of specific oligonucleotide probes to the product. These methods generally require post-amplification handling of the PCR product, thereby increasing turn-round time as well as the possibility of PCR contamination. The $\operatorname{TaqMan}^{\mathbb{B}}$ technology obviates the need for postamplification detection and confirmation by the use of a fluorescently labelled probe to detect, confirm and quantify the PCR product. During the extension phase of the PCR cycle, the $5^{\prime}-3^{\prime}$ exonuclease activity of the Taq-polymerase cleaves the specifically hybridised fluorogenic probe, resulting in an increase of fluores-

Received 16 June 2000; revised version received 6 Oct. 2000; accepted 8 Nov. 2000.

Corresponding author: Professor C.H. Wirsing von König (e-mail: wvk_hyg@klinikum-krefeld.de). cence emission. This assay format allows kinetic analysis of PCR product synthesis [13, 14]. In this study, a TaqMan ${ }^{\mathbb{R}}$ assay was developed for the detection of $B$. pertussis and $B$. parapertussis from nasopharyngeal swabs and aspirates and compared with conventional culture of clinical samples.

\section{Materials and methods}

\section{Bacterial isolates and patient specimens}

For optimisation of the PCR protocol, fresh isolates of $B$. pertussis and B. parapertussis were used. Colonies from Charcoal Agar (Oxoid, Wesel, Germany) containing defibrinated horse blood $10 \%$ and cephalexin $40 \mathrm{mg} / \mathrm{L}$ were suspended in phosphate-buffered saline (PBS) buffer to an optical density of 0.5 at $600 \mathrm{~nm}$, corresponding to $1.0 \times 10^{9} \mathrm{cfu} / \mathrm{ml}$ for $B$. pertussis and $B$. parapertussis [15] and diluted in 10-fold steps. For preliminary comparison of TaqMan ${ }^{\circledR}$ PCR with culture, spiked swabs were produced by immersing dacron swabs (Hain Diagnostika, Nehren, Germany) into the different dilutions for $10 \mathrm{~s}$. Swabs were held in Amies medium with charcoal (Hain Diagnostika) at room temperature for $48 \mathrm{~h}$ to simulate transportation.

As controls for determination of specificity, isolates of B. bronchiseptica, B. trematum, Haemophilus influenzae, $\beta$-haemolytic streptococci, Corynebacterium spp., Staphylococcus epidermidis, Neisseria spp., Staph. aureus, Enterococcus spp., Streptococcus pneumoniae, Moraxella catarrhalis and viridans streptococci were 
suspended in PBS to an $\mathrm{OD}_{600}$ of 1.0. DNA extracted from $B$. holmesii ATCC 51541 (kindly donated by U. Reischl) was also used for specificity testing.

A total of 182 clinical samples (40 nasal swabs, 121 nasopharyngeal swabs, 12 nasopharyngeal aspirates, 8 pharyngeal swabs, 1 tracheal swab) was obtained from 153 inpatients and outpatients with or without symptoms of pertussis (74 male, 78 female), including one post-mortem sample (sex unknown). The patients ranged in age from 10 days to 75 years, with a mean of 62 months and a median of 22 months. Swabs were immersed in Amies medium with charcoal during transport; aspirates were sent without additives.

All specimens (spiked swabs and clinical samples) were plated on to charcoal agar, which was incubated at $37^{\circ} \mathrm{C}$ for 7 days. Swabs were then placed in $150 \mu \mathrm{l}$ of PBS, swirled vigorously and squeezed out to elute any bacteria. If necessary, samples were stored at $-20^{\circ} \mathrm{C}$.

\section{PCR}

DNA was extracted with a QIAamp DNA Mini Kit (Qiagen, Hilden, Germany) according to the manufacturer's protocol. Primers and probes for PCR were designed by Primer Express software (PE Applied Biosystems, Weiterstadt, Germany) from the repeated insertion sequences IS481 ( $B$. pertussis) and IS1001 (B. parapertussis) $[16,17]$. The fluorescent reporter dye at the $5^{\prime}$ end of the TaqMan probe was 6carboxyfluorescein (FAM); the quencher dye at the 3' end was 6-carboxytetramethylrhodamine (TAMRA). Primers and probes are listed in Table 1. PCR was performed in two separate vials for $B$. pertussis and $B$. parapertussis; $5 \mu \mathrm{l}$ of extracted DNA were added to $45 \mu \mathrm{l}$ of a master mix. The final PCR reaction mix contained PCR buffer with ROX (6-carboxy-X-rhodamine) as a passive reference, $4 \mathrm{mM} \mathrm{MgCl}_{2}, 200 \mu \mathrm{M}$ ATP, CTP and GTP, $400 \mu \mathrm{M}$ UTP, AmpliTaq Gold polymerase $1.25 \mathrm{U}$, uracil-N-glycosylase $0.5 \mathrm{U}, 900 \mathrm{nM}$ primer PPert and APPert and $300 \mathrm{nM}$ probe SPert, or $300 \mathrm{nM}$ primer PParaP and APParaP and $300 \mathrm{nM}$ probe SParaP, for detection of $B$. pertussis and $B$. parapertussis, respectively. All PCR reagents except ATP, CTP and GTP (Roche, Mannheim, Germany) were purchased from PE Applied Biosystems.
Amplification was performed in an ABI Prism 7700 Sequence Detection System (PE Applied Biosystems) for $2 \mathrm{~min}$ at $50^{\circ} \mathrm{C}, 15 \mathrm{~min}$ at $95^{\circ} \mathrm{C}$ followed by 45 cycles of $15 \mathrm{~s}$ at $95^{\circ} \mathrm{C}$ and $1 \mathrm{~min}$ at $57^{\circ} \mathrm{C}$. Results were analysed by Sequence Detection (SD) software (PE Applied Biosystems). For determination of specificity, amplification products of $B$. pertussis, B. parapertussis and other control strains were analysed on agarose $1.5 \%$ gels containing ethidium bromide $0.005 \%$.

\section{Results}

PCR was optimised for each set of primers by adjusting $\mathrm{MgCl}_{2}$, primer, probe and Taq polymerase concentration as well as cycle number and temperature. Increase of fluorescence intensity above a given threshold value as defined by SD software was scored as a positive result. A 'normalised reporter signal' is generated during each cycle by dividing the intensity of the reporter dye by the intensity of the passive reference. A positive signal is generated when the normalised reporter signal reproducibly exceeds the background fluorescence. The cycle in which the fluorescence intensity exceeds the threshold value is defined as threshold cycle $\left(\mathrm{C}_{\mathrm{T}}\right)$. This cycle is dependent on the starting template copy number in a given PCR sample.

Analytical sensitivity was assessed by extraction and amplification of serial dilutions of suspensions of $B$. pertussis and $B$. parapertussis in PBS. The assay was able to detect $0.1-1 \mathrm{cfu}$ and $1-10 \mathrm{cfu}$ of $B$. pertussis and $B$. parapertussis, respectively, based on extraction of $1 \mathrm{ml}$ of each dilution step. Both assays showed linearity over the whole range of eight 10-fold dilutions, as shown for B. parapertussis in Fig. 1. When spiked swabs were analysed by PCR and culture the TaqMan ${ }^{\circledR}$ assay improved sensitivity $10^{3}-10^{4}$-fold for B. pertussis and B. parapertussis.

The primer and probe combination PParaP/APParaP/ SParaP was able to amplify and detect $B$. parapertussis DNA specifically. With primer and probe combination PPert/APPert/SPert, positive signals were obtained for $B$. pertussis as well as for B. holmesii. DNA extracted from Neisseria spp. and $H$. influenzae showed some non-specific amplification products when analysed on agarose gel, but neither strain produced a positive signal with the TaqMan ${ }^{\circledR}$ PCR assay.

Table 1. Sequences of the oligonucleotide primers and probes

\begin{tabular}{ll}
\hline Oligonucleotide & Sequence $\left(5^{\prime}\right.$ to $\left.3^{\prime}\right)$ \\
\hline B. pertussis - sense primer (PPert) & ATCAAGCACCGCTTTACCC \\
B. pertussis - antisense primer (APPert) & TTGGGAGTTCTGGTAGGTGTG \\
B. pertussis - probe (SPert) & FAM-AATGGCAAGGCCGAACGCTTCA-TAMRA \\
B. parapertussis - sense primer (PParaP) & GATATCAACGGGTGACGGATC \\
B. parapertussis - antisense primer (APParaP) & GTATGCCAACCCAGTTCGAA \\
B. parapertussis - probe (SParaP) & FAM-TGCTGCAATCGAGCAACGTGCA-TAMRA \\
\hline
\end{tabular}

Letters given in bold indicate fluorescent tags (see Materials and methods). 


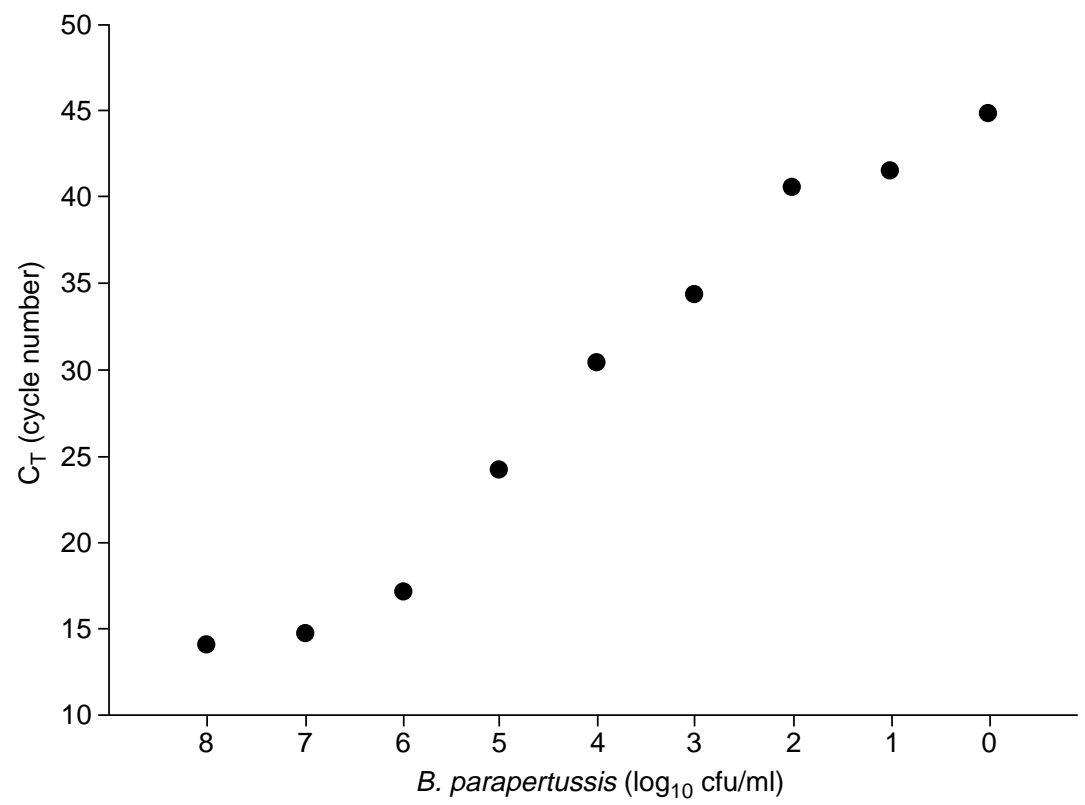

Fig. 1. Scatter plot of $\mathrm{C}_{\mathrm{T}}$ against the number of $\mathrm{cfu} / \mathrm{ml}$ of $B$. parapertussis in the bacterial suspensions used for DNA extraction and PCR assay. $\mathrm{C}_{\mathrm{T}}$ is the threshold cycle, the PCR number at which the fluorescence intensity reaches a defined threshold value.

Intra-assay variation in 10 separate assays was found to be $1.4 \%$ and $4.0 \%$ for B. pertussis and B. parapertussis, respectively. Inter-assay variation of the same sample on five consecutive days was $3.8 \%$ and $4.9 \%$, respectively.

Clinical samples were assayed in duplicate and, with discrepant results, PCRs were repeated in duplicate. Less than $5 \%$ of the results were discrepant - six specimens for B. pertussis and 10 for B. parapertussis. All except five samples were resolved by repeating the PCR. These five specimens were regarded as negative for further evaluation.

Of the total of 182 samples, 17 specimens $(9.3 \%)$ from 14 patients were positive by conventional culture. Eleven specimens from nine patients yielded $B$. pertussis, five specimens from four patients gave $B$. parapertussis, one specimen gave both. PCR gave positive signals for 51 samples $(28.0 \%)$ from 40 patients; 43 were positive for $B$. pertussis (33 patients), six for B. parapertussis (five patients) and two for both (two patients).
Of the 182 samples, 148 specimens were from 120 patients (56 male, 63 female, 1 sex unknown; age 1 month to 20 years), who presented with symptoms of pertussis. In this subpopulation, 45 specimens (30.4\%) were positive for $B$. pertussis by PCR (35 of 120 patients), whereas only 12 samples $(8.1 \%)$ were positive by culture (10 of 120 patients). Seven samples (4.7\%) were positive for B. parapertussis by PCR (6 of 120 patients), and five (3.4\%) samples were culture positive for $B$. parapertussis (4 of 120 patients) (Table $2)$. With PCR, two patients were positive for $B$. pertussis and $B$. parapertussis, whereas in culture only one sample showed a co-infection.

All culture-positive samples were considered true positives for PCR. One culture-positive sample was negative by PCR. Specimens positive by PCR only were resolved by review of patient history. Twenty-four of 28 patients who were culture-negative and PCRpositive met the CDC (Centers for Disease Control, USA) clinical case definition for pertussis (a cough illness lasting at least 2 weeks with paroxysms of coughing, inspiratory whoop or post-tussive vomiting)

Table 2. Sensitivity of real-time PCR for clinical specimens in relation to clinical symptoms

\begin{tabular}{lclc}
\hline Clinical data & $\begin{array}{c}\text { Number (\%) of } \\
\text { culture-positive samples }\end{array}$ & $\begin{array}{l}\text { Organism } \\
\text { detected }\end{array}$ & $\begin{array}{c}\text { Number (\%) of real-time } \\
\text { PCR-positive samples }\end{array}$ \\
\hline Paroxysms $(\mathrm{n}=148)$ & $12(8.1)$ & B. pertussis & $45(30.4)$ \\
No paroxysms $(\mathrm{n}=34)$ & $5(3.4)$ & B. parapertussis & $7(4.7)$ \\
& 0 & B. pertussis & 0 \\
& 1 & B. parapertussis & $1^{*}$ \\
\hline
\end{tabular}

*A 4-month-old girl with upper respiratory tract infection. 
(http://www.cdc.gov/nip/publications/sury-manual/ pertussi.pdf). The other four PCR-positive patients, although not meeting the CDC definition, had paroxysms of shorter duration.

The second subpopulation consisted of 34 specimens from 33 patients without clinical signs of pertussis (18 male, 15 female; age 10 days to 75 years). All except one sample were negative in PCR and culture. A swab from a 4-month-old girl yielded B. parapertussis and was positive for $B$. parapertussis by PCR. The patient's history showed an upper respiratory tract infection without paroxysms.

The diagnostic sensitivity of the TaqMan ${ }^{\circledR}$ assay was $94.1 \%$ when compared with culture. When compared with clinical symptoms, no sample from a patient without symptoms compatible with pertussis was positive in PCR, giving the assay a diagnostic specificity approaching $100 \%$. The proportional increase of positive specimens by PCR - defined as PCR-positive culture-negative samples divided by the number of culture-positive samples - was $206 \%$.

\section{Discussion}

This paper describes the evaluation of a real-time TaqMan $^{B}$ PCR assay for the detection of B. pertussis and $B$. parapertussis from nasopharyngeal swabs and aspirates. As described for other PCR systems $[5,6,8,9,12,18]$, the $\operatorname{TaqMan}^{\circledR}$ assay showed increased sensitivity over culture for detection of $B$. pertussis and $B$. parapertussis, and the detection rate of patients positive for $B$. pertussis or B. parapertussis, or both, was more than doubled. Similar increases in sensitivity through PCR have been observed in other published studies $[1,12]$. At the same time, the assay seems highly specific. For all culture-negative, PCRpositive cases the clinical picture was compatible with a diagnosis of pertussis. It has to be kept in mind that $B$. holmesii also gave positive signals in the $B$. pertussis PCR, as demonstrated previously [19]. This appears to be due to the presence of IS481-like sequences in the B. holmesii genome (U. Reischl, personal communication). The clinical significance of this finding is not yet fully understood because, so far, $B$. holmesii has been isolated only infrequently from nasopharyngeal specimens [20,21].

Reproducibility of the TaqMan ${ }^{\circledR}$ PCR was good, with intra- and inter-assay variation $<5 \%$. Furthermore, the TaqMan $^{\circledR}$ assay shows advantages over conventional PCR protocols. It eliminates the need for postamplification handling, thereby reducing the risk of contaminating the PCR, and decreases the total analysis time to $<4 \mathrm{~h}$. This is particularly helpful for rapid diagnosis of pertussis in children with life-threatening disease. TaqMan ${ }^{\mathbb{B}}$ PCR obviates gel electrophoresis with ethidium bromide and contact with hazardous chemicals. It achieves high specificity and sensitivity by use of a specific probe, without the need for a nested PCR protocol. Real-time TaqMan ${ }^{\mathbb{B}}$ PCR might also be suitable for a duplex ( $B$. pertussis and $B$. parapertussis) PCR, thereby increasing cost efficiency. Finally, it is well suited for quantification of genome copies, which has been advocated for research and routine pertussis diagnostics [7]. However, it is doubtful whether pre-analytic steps (e.g., obtaining nasopharyngeal swabs) can be standardised for quantification, and clinical implications of quantitative results have not been specified so far. In conclusion, real-time TaqMan $^{\circledR}$ PCR offers a fast and economical tool with high sensitivity and specificity for the diagnosis of $B$. pertussis and $B$. parapertussis infections.

We thank Dr Udo Reischl for helpful discussions. This work was supported by a grant from the Bundesministerium für Bildung und Forschung (BMBF) (PID-ARI-Net).

\section{References}

1. Farrell DJ, Daggard G, Mukkur TKS. Nested duplex PCR to detect Bordetella pertussis and Bordetella parapertussis and its application in diagnosis of pertussis in nonmetropolitan Southeast Queensland, Australia. J Clin Microbiol 1999; 37: 606-610.

2. Fredricks DN, Relman DA. Application of polymerase chain reaction to the diagnosis of infectious diseases. Clin Infect Dis 1999; 29: 475-488.

3. He Q, Schmidt-Schläpfer G, Just $\mathrm{M}$ et al. Impact of polymerase chain reaction on clinical pertussis research: Finnish and Swiss experiences. J Infect Dis 1996; 174: 1288-1295.

4. Furuya D, Yagihashi A, Endoh $\mathrm{T}$ et al. Simultaneous amplification of Bordetella repeated insertion sequences and toxin promotor region gene by polymerase chain reaction. Immunopharmacol Immunotoxicol 1999; 21: 55-63.

5. Matthews RC, Golbang N, Brück WM et al. Semiquantitative polymerase chain reaction enzyme immunoassay for the diagnosis of pertussis. Eur J Clin Microbiol Infect Dis 1999; 18: $748-750$

6. Loeffelholz MJ, Thompson CJ, Long KS, Gilchrist MJR. Comparison of PCR, culture, and direct fluorescent-antibody testing for detection of Bordetella pertussis. J Clin Microbiol 1999; 37: 2872-2876.

7. Erlandsson A, Backman A, Nygren M, Lundeberg J, Olcén P. Quantification of Bordetella pertussis in clinical samples by colorimetric detection of competitive PCR products. APMIS 1998; 106: 1041-1048.

8. Hallander HO. Microbiological and serological diagnosis of pertussis. Clin Infect Dis 1999; 28 Suppl 2: S99-S106.

9. Reizenstein E, Lindberg L, Möllby R, Hallander HO. Validation of nested Bordetella PCR in pertussis vaccine trial. $J$ Clin Microbiol 1996; 34: 810-815.

10. Douglas E, Coote JG, Parton R, McPheat W. Identification of Bordetella pertussis in nasopharyngeal swabs by PCR amplification of a region of the adenylate cyclase gene. $J$ Med Microbiol 1993; 38:140-144.

11. Li Z, Jansen DL, Finn TM et al. Identification of Bordetella pertussis infection by shared-primer PCR. J Clin Microbiol 1994; 32: 783-789.

12. Reizenstein E. Diagnostic polymerase chain reaction. Dev Biol Stand 1997; 89: 247-254.

13. Holland PM, Abramson RD, Watson R, Gelfand DH. Detection of specific polymerase chain reaction product by utilizing the $5^{\prime} \rightarrow 3^{\prime}$ exonuclease activity of Thermus aquaticus DNA polymerase. Proc Natl Acad Sci USA 1991; 88: 7276-7280.

14. Livak KJ, Flood SJM, Marmaro J, Giusti W, Deetz K. Oligonucleotides with fluorescent dyes at opposite ends provide a quenched probe system useful for detecting PCR product and nucleic acid hybridization. PCR Methods Appl 1995; 4: 
$357-362$.

15. van der Zee A, Agterberg C, Peeters M, Schellenkens J, Mooi FR. Polymerase chain reaction assay for pertussis: simultaneous detection and discrimination of Bordetella pertussis and Bordetella parapertussis. J Clin Microbiol 1993; 31: 2134-2140.

16. McLafferty MA, Harcus DR, Hewlett EL. Nucleotide sequence and characterization of a repetitive DNA element from the genome of Bordetella pertussis with characteristics of an insertion sequence. J Gen Microbiol 1988; 134: 2297-2306.

17. van der Zee A, Agterberg C, van Agterveld M, Peeters M, Mooi FR. Characterization of IS1001, an insertion sequence element of Bordetella parapertussis. J Bacteriol 1993; 175: $141-147$.

18. Lind-Brandberg L, Welinder-Olsson C, Lagergård T, Taranger
J, Trollfors B, Zackrisson G. Evaluation of PCR for diagnosis of Bordetella pertussis and Bordetella parapertussis infections. J Clin Microbiol 1998; 36: 679-683.

19. Loeffelholz MJ, Thompson CJ, Long KS, Gilchrist MJR. Detection of Bordetella holmesii using Bordetella pertussis IS481 PCR assay. J Clin Microbiol 2000; 38: 467.

20. Yih WK, Silva EA, Ida H, Harrington N, Lett SM, George H. Bordetella holmesii-like organisms isolated from Massachusetts patients with pertussis-like symptoms. Emerg Infect Dis 1999; 5: 441-443.

21. Mazengia E, Silva EA, Peppe JA, Timperi R, George H. Recovery of Bordetella holmesii from patients with pertussislike symptoms: use of pulsed-field gel electrophoresis to characterize circulating strains. J Clin Microbiol 2000; 38: 2330-2333. 